\title{
Analysis of the Reasons for Infidelity in Women with Extra-marital Relationships: A Qualitative Study
}

\author{
Shima Messripour ${ }^{1}$, Ozra Etemadi ${ }^{2}$, Seyed Ahmad Ahmadi ${ }^{3} \&$ Rezvanosadat Jazayeri ${ }^{4}$ \\ ${ }^{1} \mathrm{PhD}$ Candidate, Department of Counseling, Faculty of Education and Psychology, University of Isfahan, \\ Isfahan, Iran \\ ${ }^{2}$ Associate Professor, Department of Counseling, Faculty of Education and Psychology, University of Isfahan, \\ Isfahan, Iran \\ ${ }^{3}$ Professor, Department of Counseling, Faculty of Education and Psychology, University of Isfahan, Isfahan, \\ Iran \\ ${ }^{4}$ Assistant Professor, Department of Counseling, Faculty of Education and Psychology, University of Isfahan, \\ Isfahan, Iran \\ Correspondence: Ozra Etemadi, Department of Counseling, Faculty of Education and Psychology Sciences, \\ University of Isfahan, Isfahan, Iran. \\ mesripoor.con110@yahoo.com/O.etemadi@edu.ui.ac.ir/sayyd_ahmadi@yahoo.com/rs.jazayeri@yahoo.com
}

Received: January 29, 2016

Accepted: February 11, 2016

Online Published: April 2, 2016

doi:10.5539/mas.v10n5p151

URL: http://dx.doi.org/10.5539/mas.v10n5p151

\begin{abstract}
Due to the higher statistics of male infidelity, the focus of previous studies has been on investigating the reasons for infidelity in this gender group. On the other hand; since marital infidelity is a phenomenon that affects every country's culture, people, and even families, the results of research studies conducted overseas cannot be fully implicated to Iranian families. To this end, this study aimed at analyzing the reasons behind infidelity in women with extra-marital relationships in the form of a qualitative study. This study was conducted through a qualitative research approach and by using the content analysis method. Participants included 11 women referred to the counseling centers in the city of Isfahan. Purposive sampling was used and continued until data saturation. Semi-structured interviews were employed as the primary method of data collection. The data were analyzed via qualitative content analysis and constant comparative analysis methods. After the examination and division of the basic concepts, 800 initial codes were extracted from interviews. The categories were created based on the codes following several reviews and summarizations on the basis of similarities. By the nature, these conceptual and abstract themes were named in three categories of intrapersonal factors, marital conflicts, and sexual reasons. The factors affecting female infidelity in this study had three dimensions. These factors included intrapersonal factors, marital conflicts, and sexual reasons. These findings can help psychologists, family counselors, and planners in the field of the social sciences identify the efficient scopes and purposes.
\end{abstract}

Keywords: infidelity, women, extra-marital relationships, intrapersonal factors, marital conflict, sexual reasons

\section{Introduction}

Marital infidelity is one of the factors threatening family structure and consequently the most fundamental sense, i.e. the sense of belonging. It also raises the fear of rejection among individuals. Moreover, marital infidelity is considered as one of the threating factors affecting performance, stability, and the endurance of marital relationships as well as one of the main reasons for divorce and the collapse of marriage (Mark, Janssen \& Milhausen, 2011; Shackelford, Besser \& Goetz, 2008). The reasons would be some behavioral elements such as improper emotional and sexual needs, opportunism, irresponsibility, and deliberate deception whose acceptance by those somehow involved in this issue is not so straightforward (Guerrero et al., 1998).

Studies conducted on the reasons behind divorce suggest that extra-marital sexual affair has been the most important factor affecting the end of marriage (Tuttle \& Davis, 2015). In other cases of divorce, research studies also show that one of the driving factors is marital infidelity (Borst, 2015). South \& Lloyd (1995) in a study reported that in one-thirds of all divorces in the United States; at least one spouse has been involved in extra-marital sexual behavior. As well, 34 percent of men and 19 percent of women in the adult groups in the 
United States have reported involvement in extra-marital sexual relationships on one stage of their life.

Higher statistics of infidelity in men has drawn many researchers to investigate the reasons for infidelity and to identify the factors in this gender group. Brand et al. (2007) in an investigation on the prevalence rate of infidelity in men and women found that if the definition of infidelity is not limited to sexual intercourse and other cases are also taken into account; not only the infidelity rate in women is not less but more cases in women will be reported. Furthermore, the findings of this study revealed that women are more likely to be separated from their husbands after infidelity and get married with the men involved (the men with whom they had illicit sexual relationship). Researchers concluded that the studies reporting higher infidelity rates in men in previous studies had some flaws in providing a broad and acceptable definition of infidelity. Reduction of the difference in the rate of infidelity between men and women is also revealed in other studies provided that the definition of marital infidelity is considered broadly (Barta \& Kiene, 2003; Buss et al., 1999). Hence, attention to the issue of female infidelity and its role in posing familial and social problems are of utmost importance.

In addition, the reasons for infidelity in women are different from those in men. There are several reasons behind female infidelity including lack of a warm and intimate relationship with their husband, women's history of debauchery, feeling of loneliness, individual factors, personality disorders, singlehood life, economic difficulties, diversity-seeking and lack of sexual satisfaction, husband's infidelity, adventure and jealousy, lack of attention and care to the woman by her husband, and further interests expressed by other men (Shackelford, Besser \& Goetz, 2008; Blow \& Hartnett, 2005; Allen et al., 2008).

Obviously, the reasons for infidelity in men is investigated more than that in women in previous studies, while the major factors cited as the causes of infidelity are based on the results of studies in Western countries. On the other hand; since marital infidelity is a phenomenon that is heavily influenced by the culture of each country, people, and even the family; the results of investigations conducted abroad cannot be fully extended to Iranian families. Given that the process of this study is based on the main research question; "What are the reasons for infidelity in women with extra-marital relationships?", the best research method for this study is a method analyzing the nature of a phenomenon in its natural context along with its structure, process, and the factors affecting its formation. Accordingly, the present study is to analyze the reasons behind infidelity in women with extra-marital relationships in the form of a qualitative study.

\section{Method}

This study is a qualitative research in the form of a content analysis method. Qualitative content analysis is defined as a research method which is used as a subjective interpretation of the content of the textual data. In this method, initial codes and themes are identified through the process of systematic classification. Content analysis is beyond the actual content extraction from textual data. Through this method, hidden themes and patterns can be revealed from the data content provided by the study participants (Elo et al., 2014).

The statistical population included all women referred to the counseling centers in the city of Isfahan. In this study, purposive sampling was used for the selection of participants and it continued until data saturation. The selection criteria for the participants in this study included women aged between 20-70 years old, extra-marital relationships, no agreement about open relationships, lasting relationships more than one night, prolonged relationships with another person, and finally no major mental disorders. Prior to the interviews, the participants were evaluated through the short form of MMPI test software to examine their mental health. After the emergence of the first categories, the selection of the next participant was based on the question that how much she can help further clarify the emerging categories. This sampling procedure was continued until data saturation. Following interviews with 9 participants, data saturation was reached in practice in this study and the initial categories were formed; however, to ensure it further, two other interviews were conducted but no new data leading to the formation of new codes and categories were obtained. Thus, a total of 11 participants were interviewed.

The main method of data collection in this study was a semi-structured in-depth interview with open-ended questions. This kind of interview is one of the most common ways of collecting data in qualitative research (Willig, 2013). The interview is also called general interview guide approach. The interview guide was pre-tested by using a pre-fabricated primary interview, some of the questions were rewritten, and other items were added to the interview. In this study, the interviewer first started the interview with general questions after receiving the demographic data. Some of the key questions to the participants included the following ones:

What is your definition of extra-marital relationships? What relationships are considered extra-marital? In what year of your marriage, did you get involved in this relationship? In your opinion, what factors are effective in extra-marital affairs? How did you manage your marital differences? What did you think about such 
relationships before engaging in them? What are the effective roles of individuals, events, or even institutions and organizations in the society in the prevalence of marital infidelity? What are your major stresses in your life? What were your attractions and your spouse's to each other at the beginning of your marriage?

Collecting and analyzing data in order to investigate the reasons for infidelity included six steps: 1 . the researcher got familiar with the data, 2. the initial codes of the data were produced, 3. a search was done for mining the themes through a review of different codes extracted in previous steps, 4 . a review was conducted for the themes and their re-comparisons with the data to ensure their accuracy, 5. themes were defined and named, and 6. the final report was prepared. Throughout the process of data collection and analysis, any reflections and notes related to the data were written down by the researcher and used for the next interviews.

The method of data analysis was in a form of constant comparative analysis which is a way to increase the reliability and validity of the data. All statements and expressions of the participants were transcribed verbatim and completely, content analysis was performed on them, and then they were coded. Therefore, the researcher was completely overwhelmed with data to gain a new understanding or insight. At first, the data analysis was started with repeated reading of texts for immersion in them and finding a quick overview. Then, the texts were read verbatim in order to extract the codes. This is a continuous process of extracting the codes to name them. After extracting the concepts and codes from important sentences and paragraphs, they were grouped into categories based on the similarities and differences, and finally the categories were combined into a quantitative number of the main category based on the relationships between them. To facilitate the main steps of the study, the qualitative research software of MAXQDA Plus 2010 v10.4.16.1 Multilingual was used.

To ensure the accuracy and reliability of the research, several methods were used during the study. In this study, four criteria for the reliability of the study were employed including acceptance, transferability, consistency, and verifiability (Silverman, 2013). One of the best ways to build credibility is long-term involvement in research. In this study, the researcher has been involved as a consultant in this field for a long time. Participant checking was also used to verify the accuracy of the extracted data and codes or modify them. To this end; after coding each interview, it was given back to the participants to ensure the integrity of the codes and their interpretations, and correct the codes that do not represent their views.

External checking was also employed. To this end, parts of the interview transcriptions along with assigned codes and created categories were submitted to some observers to review the process of analysis and leave their comments regarding their accuracy. To determine the proportionality, the research findings were also shared with non-participant individuals, and they confirmed their goodness of fit. Sampling techniques with maximum diversity which contribute to the fitness or transferability of the findings to others were also used in this study. For the verifiability and accountability of the research, the researcher accurately recorded and reported the research steps and processes for follow-up investigations. This study was approved by the Ethics Committee of the University of Isfahan. Prior to the investigation, the approval of the relevant authorities was obtained.

\section{Results}

A total of 15 women were included in this study, but 3 of them were excluded due to their bipolar disorder, and 1 was crossed out because of sex addiction. The demographic data of the participants are represented in Table 1. After the examination and separation of the basic concepts, 800 initial codes were collected from the interviews. The categories were created based on the codes and repeated reviews and summarizations and according to the similarities. With more reviews and comparisons of categories, their internal meanings in the form of primary themes were identified. By nature, these themes were named conceptual and abstract. Accordingly, these themes brought about the reasons behind infidelity. These categories included (1) intrapersonal factors, (2) marital conflicts; and (3) sexual reasons.

Table 1. The Demographic data of study participants

\begin{tabular}{rrrrrrr}
\hline $\begin{array}{r}\text { Monthly } \\
\text { Income (riyal) }\end{array}$ & $\begin{array}{r}\text { Number of } \\
\text { children }\end{array}$ & $\begin{array}{r}\text { Number of } \\
\text { disclosed } \\
\text { Relationships }\end{array}$ & $\begin{array}{r}\text { Year of starting } \\
\text { secret Relationships }\end{array}$ & $\begin{array}{r}\text { Age at } \\
\text { Marriage } \\
\text { time }\end{array}$ & participants \\
\hline 6000000 & 1 & 1 & 2 & 22 & 33 & 1 \\
4000000 & 0 & 1 & 1 & 20 & 28 & 2 \\
8000000 & 2 & 2 & 5 & 18 & 47 & 3 \\
11000000 & 3 & 3 & 10 & 16 & 65 & 4 \\
14000000 & 2 & 1 & 6 & 21 & 53 & 5
\end{tabular}




\begin{tabular}{rrrrrrr}
5000000 & 1 & 1 & 1 & 24 & 29 & 6 \\
6000000 & 1 & 1 & 3 & 23 & 34 & 7 \\
15000000 & 2 & 1 & 4 & 20 & 46 & 8 \\
8000000 & 2 & 1 & 2 & 21 & 38 & 9 \\
9000000 & 1 & 1 & 1 & 30 & 35 & 10 \\
4000000 & 0 & 1 & 1 & 17 & 22 & 11 \\
\hline
\end{tabular}

Since the research method was of content analysis type and there was no graphical model, only one conceptual model can be presented for the reasons as follows in Figure 1:

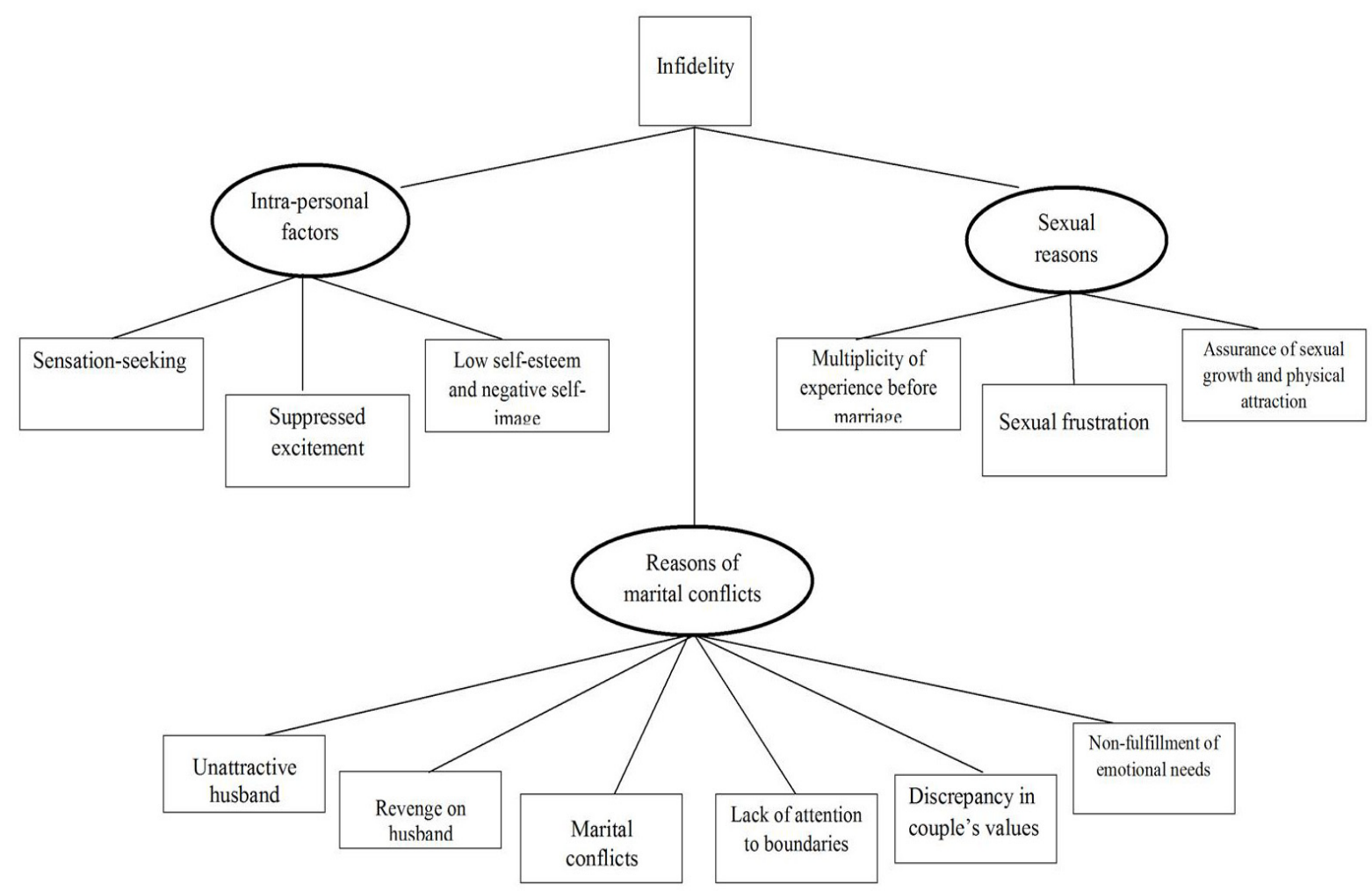

Figure 1. The Graphical Model of Marital Infidelity

\section{(1) Intrapersonal Factors}

In this category, concepts emanating from individual characteristics such as personality traits or genetics of individuals were provided. These factors were classified into three subcategories of sensation-seeking, low self-esteem and negative self-image, and suppressed excitement.

\section{Sensation-Seeking}

A sense of weariness and frustration with marital life due to mental characteristics is one of the issues mentioned by the participants. In this regard, a participant stated that:

"I do not know whether life has just become boring for me or not."

Boredom was accompanied by some experiences for some of the participants and a sense of curiosity among others. Women's experiences were related to psychological characteristics before marriage. A participant said:

"I was very naughty since my singlehood. I could not have fun with my husband, but I was in a good mood with somebody else."

Due to lack of experience, other participants had developed a strong sense of curiosity. A participant mentioned that:

"You know that I have not gone through such a relationship during my singlehood and I just wanted to see what 


\section{it feels like."}

Another participant maintained that:

"Sexual relationship with somebody else was as whole a new experience."

Finally, a participant considered the satisfaction of her sensation-seeking needs through having such a relationship as revealed in:

"Just having an affair like that was interesting to me."

\section{Low self-Esteem and Negative Self-Image}

Of the factors associated with individual characteristics was low self-esteem and negative self-image. The participants stated that they did not have enough charm which led to one of the reasons behind low self-esteem among them. In this line, participants said that:

"I was not attractive from others' perspectives. In fact, he was the first person who had too much attention to me."

"I just wanted to see if I am not lovely to my husband; or nobody else loves me. So, such a dependency was created between us."

\section{Suppressed Excitement}

The interviewees mentioned themselves as mentally emotional people. A participant hihglighted that:

"I have always had an active inner child."

However, the participants emphasized that such an excitement in life was suppressed by their spouses. In this regard, a participant said that:

"Whatever I did to say I love you to my husband was ineffective because he always said that it is not right to our age. He always called me a kid. There was no love in our marital life."

\section{(2) Marital Conflicts}

Marital conflicts refer to the interactions and reactions between a woman and her husband. This category was composed of unfulfilled emotional needs, instability and difference in couple's values, lack of attention to boundaries, marital discord, revenge on the husband, and unattractive husband.

\section{Non-Fulfillment of Emotional Needs}

One of the most important expressions of the interviewees was the non-fulfillment of emotional needs by their husbands. Participants stated that:

"We do not ever talk with each other."

"My wife was cheerful with others outside the house, but gloomy for me at home."

"Generally, I had forgotten myself in life with its own feelings and needs."

Women's need of attention and care from their husbands was mentioned as one of the most important emotional needs.

"He did not care about me and all his attention was instead to his family and I have always had a feeling of psychological emptiness."

"In my life, I was always looking for something to fill my loneliness time."

\section{Discrepancy in Needs and Goals}

The women in this study maintained that their husbands do not have a good understanding of their need fulfillment. One of the basic demands of women was their husbands' honesty.A participant in this respect said that:

"I expected him to be honest with me, but he was not honest."

In some cases, these demands were expressed in economic needs.

"A husband must meet all the economic needs of his wife, but my husband did not pay heed to these needs."

In addition, discrepancy in goals as well as in mutual understanding by husbands was cited by women.

"My husband and I did not have the same goals in life. We did not ever have a similar goal."

"My husband did not understand me." 
"We always had to argue with each other for a long time to understand the slightest things."

"I wanted my needs be fulfilled without expressing them, but my husband did not realize them and I always resorted to force and cheating."

\section{Lack of Attention to Boundaries}

Failure to comply with privacy and settled boundaries in marital life was another factor that was seen in women as well as their spouses. Interviewee' husbands did not have any emphasis on family privacy; in this regard, the participants stated that:

"My husband was in good terms with his unmarried friends, and this caused closer contacts with them."

"We were constantly in contact with relatives and strangers."

In some cases, crossing the red line by a woman was a similar reaction to the lack of boundaries in relationships by his husband. A participant said that:

"My husband had an open relationship with my friends."

Moreover, non-adherence to these boundaries may change and reduce susceptibility to these boundaries over time; some participants maintained that:

"All my colleagues at work almost always talk about these relationships."

"Family does not make any sense to me and it is just meaningful for our parents."

\section{Marital Discord}

Participants expressed that they faced with a variety of differences in their marital life. These differences included permissions to others for intervention in marital life, husband's addiction, and discrepancy in couple's roles. In this respect, participants reiterated that:

"My mother-in-law is involved in all the events of our marital life and it is driving me crazy."

"From the first day of our marriage, I had only one condition that my husband must not have addiction, but he became a substance abuser at the end."

"I had to keep visiting my husband' original family, but he did not have the same responsibility towards my family."

"My role was just bringing up children. He just thought about his own progress and growth, and how to climb the success ladder"

"He could not remember the common life events in our marital life; and when I complained, he just kept saying that you are behaving like a child."

"Every time I talked to him about my worries, we fought; and if I did not talk about them, I was suspected with secrecy. Generally, I did not have any other option."

"We only argued and fought in the house."

\section{Revenge on the Husband}

Husbands' annoying behaviors and reactions such as lack of affection, relationships with other women or talks about the relationships were considered as the factors that encouraged women to react or take revenge on their husbands. Participants maintained that:

"I told him I love you a thousand times, but he did not pay any attention."

"I always knew that he had the desire to marry my sister."

"He used to talk about lots of former girlfriends and his relationships with them."

"A voice inside me always enticed me to prove myself and show that I am not inferior to him."

"I mentioned a hundred times that if you do not change your behavior, I will behave in the same way, but he was indifferent."

"He always thought that he was just attractive and handsome."

\section{Unattractive Husband}

Unattractive husband was of the factors affecting marital conflicts. Lack of attraction could be present from the beginning of the marriage or after marriage due to changes in couple's appearance. Participants in this regard said that: 
"I did not love him from the beginning."

"I hate my husband's height and physique."

"My husband did not dress up."

"My friends, relatives, or neighbors almost always told me that it is a pity that you got married with such a person".

"After my husband's addiction, I could not tolerate his appearance"

"I always imagined my ex-boyfriend's face in my mind and I felt regretful"

"I wish my husband kept himself attractive like all other men".

\section{Sexual Reasons}

Factors related to the sexual needs of women were placed in this category. These factors were grouped into the three sub-categories of curiosity for sexual experiences, sexual experiences before marriage, and sexual frustration.

\section{Curiosity for Sexual Experiences}

Some women mentioned the examination of their sexual growth and getting ensured of the ability to have complete sexual intercourse as the reasons behind their marital infidelity. In this sub-category, participants maintained that:

"I wanted to see if I have a G-spot like other women."

"I did not know I have had the ability to satisfy my husband."

"I wanted to get ensured by another person other than my husband that I have no problems with my sex."

"I wanted to be confirmed by another man in terms of sexual attraction before my husband came back from the U.S."

"My wife always had no feedbacks to me although I had training courses in this regard. He always told me you are good but I knew from the beginning that he is just telling lies."

"I was fond of having sex with people much smaller or much larger than me."

\section{Sexual Experiences before Marriage}

Having sexual relationships and its continuation, willingly or unintentionally, after marriage was emphasized as one of the sub-categories of sexual reasons. Participants in this regard stated that:

"I was ignoring such relationships, but my phone always rang."

"I constantly ran across my boyfriend on Facebook, I was enticed."

"Singlehood life was full of enticement and thrill."

"I did not have any orgasm in my sexual affaires with my husband."

"Before marriage, I used to experience a sex style a day."

"I should say that I was addicted to sex."

"The only time I had fun all my lifetime was during my singlehood life. I had lots of sex and relationships with my former boyfriends."

"To escape home after quarrels, I used to sleep with a man and had sex. I got accustomed to this and I could not kick this habit after marriage."

\section{Sexual Frustration}

Lack of sexual need fulfillment or complaints about sexual relationships with husband were the other factors associated with extra-marital relationships. Participants expressed that:

"I did not know the meaning of sexual relationship."

"Every time I told him come and sleep together, he ridiculed me and called me names like a harlot."

"The nights we had arguments, he did not sleep on our bedroom"

"We did not have sex every 4 months."

"He always knew the fulfillment of a woman's needs trivial." 
"Every night; when he was satisfied, he had a beauty sleep."

"I regret that I could not understand the meaning of romantic or sexual relationship."

"Every time I wore a new dress or make-up, he called me by using bad and unpleasant names so overall I felt cold feet."

"I had an orgasm with anyone except my husband."

"Every night, he slept far from me on his backside with excuses such as I am tired, I am not in a mood, it is a sin to have sex tonight. Sometimes I cried to sleep."

\section{Discussion}

To help people involved in extra-marital relationships, there is a need to have a good understanding of the features, capabilities, and needs of couples because the occurrence of this traumatic event in life encounters couples with a major crisis. Therefore, the aim of this study was to better understand the factors contributing to infidelity in women. After coding and categorization, the content analysis of the interviews indicated that the reasons behind marital infidelity can be grouped into three categories of intrapersonal factors (sensation-seeking, low self-esteem and negative self-image, and suppressed excitement), marital conflicts (unfulfilled emotional needs, instability and difference in couple's values, lack of attention to boundaries, marital discord, revenge on the husband, and unattractive husband), and sexual reasons (curiosity for sexual experiences, sexual experiences before marriage, and sexual frustration).

In line with this study, many other previous studies have also noted the importance of individual factors and motivations to have extra-marital affairs (Shackelford, Besser \& Goetz, 2008, Allen et al., 2008, Whisman, Gordon \& Chatav, 2015). Atwood \& Seifer (1997) in their study in the area of individual differences found attitudes and beliefs of people about love, confidence-building, and problems regarding intimacy as the most important factors affecting the occurrence of extra-marital relationships.

Consistent with the results of this study, other investigations have also suggested that some of the extra-marital relationships originate from marital life frustration. In this regard, sensation-seeking as a reaction against frustration is considered as one of the most important factors in predicting infidelity (Yeniceri \& Kökdemir, 2006). It seems that the personality traits of sensation-seeking people are associated with the risk of sexual behaviors which are new, diverse, and impulsive. Accordingly, such individuals have more sexual partners and are inclined to high-risk sexual behaviors and permissive attitudes towards sex (Zuckerman, 2007). In line with the results of this study, the spirit of adventure in some women along with non-responsiveness and in some cases their suppression by their husbands have been mentioned in other studies (Young et al., 2000). On the other hand; in order to maintain and strengthen their self-esteem and self-image, women involved in infidelity are trying to demonstrate through their behavior that their self-esteem is high and there is no problem in this regard. These groups of people are seeking relationships outside the family system to prove themselves (Wiggins \& Lederer, 1984).

In this study, marital conflicts are considered the important factors affecting female infidelity. According to the Theory of Need Fulfillment by Drigotas and Rusbult (1984), relationships and the possibility of satisfaction fulfill four requirements in addition to the sexual needs. These needs include intimacy, friendship, security, and emotional relationships. These five relationships are not usually met in a desirable way in marital relationships which have led to problems in relationships between couples such as lack of commitment to husband.In this study, the non-fulfillment of emotional needs was taken into account as the basic sub-category of marital discord. Atwood and Siffer (1997) mentioned the problems associated with intimacy and failure to meet the emotional needs of husband as the reasons for engaging in extra-marital relationships. Lack of coordination and instability in common goals were included among the other sub-categories of this area. In their theory, Buunk \& Dijkstra (2000) stated that if a person believes that their current relationships have few capabilities to expand capacities, it is likely that they would establish new relationships to compensate for them.

In this study, permissive beliefs and values and no attention to the boundaries of sexual issues are related to infidelity to husband. In agreement with this investigation, other studies also considered individual attitudes and orientations towards husband's relationships among the high-risk interpersonal variables (Weiser et al., 2015). It should be noted that people who engage in extra-marital relationships have more permissive attitudes towards this issue (Buunk \& Bakker, 1995). Although some people who always consider these issues wrong get involved. However, studies indicate that individuals and generally couples with more permissive attitudes about the observance of ethical boundaries in their families are more likely to engage in infidelity and related behaviors (Hackathorn et al., 2011). 
Marital conflicts are also associated with higher rates of infidelity in relationships. With few exceptions, studies showed that there is a relationship between infidelity and marital conflicts. The study by Allen \& Rhoades (2007) demonstrated that in couples wherein women get involved in infidelity in the first year of their marital life, mutual relationships with husband are significantly negative and the couples mutually contempt each other. Other investigations have also stressed that women's infidelity is closely linked with marital conflicts and dissatisfaction; however, male infidelity is further associated with sexual dissatisfaction.

According to the results of this study, women may revenge and choose infidelity due to their resentment with their husbands. For example, a woman who is pessimistic to her husband or hears his words about relationships before marriage is placed under pressure and tends to revenge by extra-marital relationships. This is common in women because they always think that they are taking revenge of their husband's wrong deeds. A research study by Guerrero \& Bachman (2008) entitled as the style of marital relationships showed that malicious relationships lead to reduction in couple's relationships and vengeance. Although during marital lifetime, couples may get fed up with their spouses' appearance or find their spouse's attractiveness monotonous and uninteresting; having the basic charm for a husband and maintaining it is one of significant factors mentioned by women involved in infidelity in this study. Li \& Kenrick (2006) also listed attractiveness as a predicting factor affecting extra-marital relationships.

The third category extracted in the area of the factors affecting women's infidelity in marital relationships in this study was associated with sexual reasons. According to the Interdependence Theory, individuals measure the pros and cons of their current relationships on the basis of two criteria. One is the comparison of the current relationship with previous expectations and perceptions of an individual about marriage and the second criterion is the comparison of the marital relationships with those with others. The outcomes and implications obtained by an individual about these two comparisons are closely related to the process of infidelity (Docan-Morgan \& Docan, 2007).

Consistent with this study, other investigations also indicated that questions about the desirability, attractiveness, and sexual capability of a person may be sufficient to cause some women seek to prove and confirm their value and attractiveness through their illicit sexual affairs (Bagarozzi, 2007). Meanwhile, those who had sex in the past were more likely to be involved in infidelity (Feldman \& Cauffman, 1991). People who are dissatisfied with their marriage are in search of sexual satisfaction elsewhere. Sexual dissatisfaction during the first year of marital life makes them vulnerable to infidelity. In line with this study, other investigations also suggested that people dissatisfied with their sexual relationships have more inclination to get involved in extra-marital relationships (Previti, 2004). In other studies, researchers examined the ability of couple's relationships to satisfy their needs and their impact on infidelity. Satisfaction of the needs can probably be regarded as an index which is effective in determining couple's marital satisfaction and ultimately its impact on extra-marital relationships (Le \& Agnew, 2001).

Marital infidelity like many other social phenomena is a multi-dimensional event in which several factors are involved. Considering the qualitative interviews in this study, the main factors affecting the occurrence of infidelity in women were intra-personal factors, sexual reasons, and marital discord. Therefore; during the examination of some cases, the researcher concluded that personal characteristics such as personality and extreme sensation-seeking in women lead to their dissatisfaction with their husbands as well as unfulfilled needs and orientation towards extra-marital relationships. But in some cases it was observed that severe marital conflicts and incorrect management of problem-solving as well as unmet emotional needs of women reduce their excitement and libido and ultimately lead to extra-marital relationships. In general, these factors are in a cyclical form and they are different in various cases. In fact, there is no cause-and-effect relationship between these components and each factor by itself cannot lead to marital infidelity or whether intra-personal issues lead to marital discord and then sexual frustration and finally marital dissatisfaction which bring about marital infidelity or whether extreme marital conflicts lead to depression or sexual frustration or sexual experience before marriage and extreme curiosities in women lead to an increase in couples' discrepancies and finally the occurrence of marital infidelity. This issue was completely different in various cases and in general the interaction and the mutual effects of these factors could lead to extra-marital relationships and no effective factor was observed by itself. The contribution of each factor was not of the purposes of this study.

Previous research studies have considered factors such as low sexual relationships, individuals' willingness to sexual relationships outside marital boundaries, and having the opportunity and time to address this type of relationships associated with non-compliance to husbands (Atkins, Jacobson and Bakom, 2001).In a study by Bahrami and Rezwan (2006), factors affecting marital infidelity were cited as follows: (a) lack of interest in spouse and forced choice, (b)wrong choice of spouse, (c) cultural and social non-compliance between couples, (d) 
unrealistic expectations of married life, (e) failure to express emotions and cold emotional relationships (c),lack of proper sex, (d) unlimited relationships between families and friends, (e)personality and emotional differences, (e) childhood conflicts and lack of satisfaction with adolescence needs, and (f) stereotyped gender schemes for the roles of women and men. The previous research also focused quantitatively on other issues and examined various aspects of infidelity. Current research studies qualitatively identify the factors affecting female infidelity and lead to increased knowledge in this area in terms of theory and therapy. The reasons of infidelity in men and women are different. In previous studies, the reasons of male infidelity have been more examined in comparison with that in women; thus, this study was to investigate the pathological reasons behind infidelity in women which create a new cycle in which a person can be examined from three aspects including intra-personal factors, interpersonal relationships with spouse, and mutual sexual problems.

In the Iranian society, family as a ladder to human perfection has a special place; and in this institution, women have a special role and status. One of the most important and serious threats to families is marital infidelity which is considered as a taboo in Iranian society, especially if it is committed by women; because they constitute the foundations of a family. The biggest limitation in this study was the topic. Given that it is a taboo, individuals hardly ever refer to counseling centers, so there were limitations in data collection and sampling. Since the study was of qualitative type and based on interviews, there were limitations in the research time, attraction of individuals' trust, and making good relationships as well as data collection and their generalization. Moreover; due to lack of access to a statistical population with the issue of marital infidelity, there was no possibility to use quantitative research.

Given that the present study was qualitative and it was not possible to find the contribution of each factor affecting the occurrence of infidelity; it is recommended to employ quantitative methods in future studies and examine the proportion of each factor by itself. In addition, the development of educational-therapeutical packages along with this study to deal with the obstacles and causes damaging marital relationships is suggested to improve couples' relationships. Given the current situation in the society; the causes of infidelity in men needs to be addressed in another qualitative research.

Iranian society considers a special sanctity for family due to its rich and Islamic culture, conduct and traditions and knows marital infidelity as a detrimental and incorrect action especially if it is committed by women. Marital infidelity due to external or personal reasons almost always brings about destructive consequences to the couples and subjects the entire family and even society to problems. Since marital infidelity is a phenomenon strongly affected by culture, ethnicity, and even family in each country; the findings of international studies cannot be completely generalized to Iranian families.

This study was to uncover the factors affecting infidelity in women in a qualitative form and develop counseling-therapeutical intervention packages following the elicitation of factors for classification. As a whole, there was no study investigating all these factors and variables. In previous studies, all these factors and their effects on women were not examined but there were studies in which the variables were examined individually.

\section{Conclusion}

The findings and discussions in this study revealed that the factors affecting infidelity in women are three-dimensional. The nature and the perception of women about these factors include intrapersonal factors, marital conflicts, and sexual reasons. These findings can help psychologists, family counselors, and planner in the field of social sciences find in what areas and for what purposes they need to do the planning and intervene. It is recommended that the results of this study be assessed in prospective studies to evaluate the predictive power of each factor.

\section{Ethical approval}

Before conducting the interviews, all the participants of the study were informed that they were included in a research project for a $\mathrm{PhD}$ thesis and they were also assured regarding their anonymity. Following a full explanation of confidentiality regulations between the researcher and the interviewee, they gave their consents to participate in this research project and their identities were not mentioned until the end of the investigation.

\section{References}

Allen, E. S., \& Rhoades, G. K. (2007). Not all affairs are created equal: Emotional involvement with an extradyadic partner. Journal of sex \& marital therapy, 34(1), 51-65. http://dx.doi.org/10.1080/00926230701620878

Allen, E. S., Rhoades, G. K., Stanley, S. M., Markman, H. J., Williams, T., Melton, J., \& Clements, M. L. (2008). Premarital precursors of marital infidelity. Family process, 47(2), 243-259. 
http://dx.doi.org/10.1111/j.1545-5300.2008.00251.x

Atwood, J. D., \& Seifer, M. (1997). Extramarital affairs and constructed meanings: A social constructionist therapeutic approach. American Journal of Family Therapy, 25(1), 55-75. http://dx.doi.org/10.1177/0192513X11424257

Bagarozzi Sr, D. A. (2007). Understanding and treating marital infidelity: A multidimensional model. The American Journal of Family Therapy, 36(1), 1-17. http://dx.doi.org/10.1080/01926180601186900

Barta, W. D., \& Kiene, S. M. (2005). Motivations for infidelity in heterosexual dating couples: The roles of gender, personality differences, and sociosexual orientation. Journal of Social and Personal Relationships, 22(3), 339-360. http://dx.doi.org/10.1177/0265407505052440

Blow, A. J., \& Hartnett, K. (2005). Infidelity in committed relationships ii: A substantive review. Journal of marital and family therapy, 31(2), 217-233. http://dx.doi.org/10.1111/j.1752-0606.2005.tb01556.x

Borst, J. B. (2015). A Systematic Review of the Effects of Family Conflict: Focusing on Divorce, Infidelity, and Attachment Style.

Brand, R. J., Markey, C. M., Mills, A., \& Hodges, S. D. (2007). Sex differences in self-reported infidelity and its correlates. Sex Roles, 57(1-2), 101-109. http://dx.doi.org/10.1007/s11199-007-9221-5

Buss, D. M., Shackelford, T. K., Kirkpatrick, L. A., Choe, J. C., Lim, H. K., Hasegawa, M., \& Bennett, K. (1999). Jealousy and the nature of beliefs about infidelity: Tests of competing hypotheses about sex differences in the United States, Korea, and Japan. Personal Relationships, 6(1), 125-150. http://dx.doi.org/10.1111/j.1475-6811.1999.tb00215.x

Buunk, B. P., \& Bakker, A. B. (1995). Extradyadic sex: The role of descriptive and injunctive norms. Journal of Sex Research, 32(4), 313-318. http://dx.doi.org/10.1080/00224499509551804

Docan-Morgan, T., \& Docan, C. A. (2007). Internet infidelity: Double standards and the differing views of $\begin{array}{llll}\text { women } & \text { and } \text { men. }\end{array}$ http://dx.doi.org/10.1080/01463370701492519

Drigotas, S. M., \& Barta, W. (2001). The cheating heart: Scientific explorations of infidelity. Current directions in psychological science, 10(5), 177-180. http://dx.doi.org/10.1111/1467-8721.00143

Elo, S., Kääriäinen, M., Kanste, O., Pölkki, T., Utriainen, K., \& Kyngäs, H. (2014). Qualitative Content Analysis. SAGE Open, 4(1), 2158244014522633. http://dx.doi.org/10.1177/1049732305276687

Feldman, S. S., \& Cauffman, E. (1999). Your cheatin'heart: Attitudes, behaviors, and correlates of sexual betrayal in late adolescents. Journal of research on Adolescence, 9(3), 227-252. http://dx.doi.org/10.1177/0192513X15581660

Guerrero, L. K., \& Andersen, P. A. (1998). The dark side of jealousy and envy: Desire, delusion, desperation, and destructive communication. The dark side of close relationships, 33-70. http://dx.doi.org/10.1007/BF02310555

Guerrero, L. K., \& Bachman, G. F. (2008). Communication following relational transgressions in dating relationships: An investment-model explanation. Southern Communication Journal, 73(1), 4-23. http://dx.doi.org/10.1080/10417940701815592

Hackathorn, J., Mattingly, B. A., Clark, E. M., \& Mattingly, M. J. (2011). Practicing what you preach: Infidelity attitudes as a predictor of fidelity. Current Psychology, 30(4), 299-311.

Hendrick, C., \& Hendrick, S. S. (2000). Close relationships: A sourcebook. Sage.

Le, B., \& Agnew, C. R. (2001). Need fulfillment and emotional experience in interdependent romantic relationships. Journal of Social and Personal Relationships, 18(3), 423-440. http://dx.doi.org/10.1177/0265407501183007

Li, N. P., \& Kenrick, D. T. (2006). Sex similarities and differences in preferences for short-term mates: what, whether, and why. Journal of personality and social psychology, 90(3), 468. http://dx.doi.org/10.1037/0022-3514.90.3.468

Mark, K. P., Janssen, E., \& Milhausen, R. R. (2011). Infidelity in heterosexual couples: Demographic, interpersonal, and personality-related predictors of extradyadic sex. Archives of sexual behavior, 40(5), 971-982. http://dx.doi.org/10.1007/s10508-011-9771

Previti, D., \& Amato, P. R. (2004). Is infidelity a cause or a consequence of poor marital quality? Journal of 
Social and Personal Relationships, 21(2), 217-230. http://dx.doi.org/10.1177/0265407504041384

Shackelford, T. K., Besser, A., \& Goetz, A. T. (2008). Personality, marital satisfaction, and probability of marital infidelity. Individual Differences Research, 6(1), 13-25. http://dx.doi.org/10.1080/10510970701518405

Silverman, D. (2013). Doing qualitative research: A practical handbook. SAGE Publications Limited.

South, S. J., \& Lloyd, K. M. (1995). Spousal alternatives and marital dissolution. American Sociological Review, 21-35.

Tuttle, J. D., \& Davis, S. N. (2015). Religion, Infidelity, and Divorce: Reexamining the Effect of Religious Behavior on Divorce Among Long-Married Couples. Journal of Divorce \& Remarriage, 56(6), 475-489. http://dx.doi.org/10.1080/10502556.2015.1058660.

Weiser, D. A., Weigel, D. J., Lalasz, C. B., \& Evans, W. P. (2015). Family Background and Propensity to Engage in Infidelity. Journal of Family Issues, 0192513X15581660. http://dx.doi.org/10.1177/0192513X15581660

Whisman, M. A., Gordon, K. C., \& Chatav, Y. (2007). Predicting sexual infidelity in a population-based sample of married individuals. Journal of Family Psychology, 21(2), 320. http://dx.doi.org/10.1037/0893-3200.21.2.320

Wiggins, J. D., \& Lederer, D. A. (1984). Differential antecedents of infidelity in marriage. American Mental Health Counselors Association Journal.

Willig, C. (2013). Introducing qualitative research in psychology. McGraw-Hill Education (UK).

Yeniceri, Z., \& Kökdemir, D. (2006). University students' perceptions of, and explanations for, infidelity: The development of the Infidelity Questionnaire (INFQ). Social Behavior and Personality: an international journal, 34(6), 639-650. http://dx.doi.org/10.2224/sbp.2006.34.6.639

Young, K. S., Griffin-Shelley, E., Cooper, A., O'mara, J., \& Buchanan, J. (2000). Online infidelity: A new dimension in couple relationships with implications for evaluation and treatment. Sexual Addiction \& Compulsivity: The Journal of Treatment and Prevention, 7(1-2), 59-74. http://dx.doi.org/10.1080/10720160008400207

Zuckerman, M. (2007). Sensation Seeking and Risk. American Psychological Association.

\section{Copyrights}

Copyright for this article is retained by the author(s), with first publication rights granted to the journal.

This is an open-access article distributed under the terms and conditions of the Creative Commons Attribution license (http://creativecommons.org/licenses/by/3.0/). 